\title{
Modulation of monthly precipitation patterns over East China by the Pacific Decadal Oscillation
}

\author{
Qing Yang ${ }^{1} \cdot{\text { Zhuguo } \mathrm{Ma}^{1} \cdot \text { Baoliang Xu}}^{1,2}$
}

Received: 14 October 2015 / Accepted: 27 March 2016/Published online: 14 April 2016

(C) The Author(s) 2016. This article is published with open access at Springerlink.com

\begin{abstract}
Previous studies suggest that the Pacific Decadal Oscillation (PDO) modulates annual and summer precipitation patterns over East China. In this study, the effect of the PDO on monthly precipitation anomalies over this region is investigated. The new results show that the effect is month-dependent. The well-known North-South dipole patterns of annual precipitation are dominated by the July-August precipitation. In other months, the corresponding patterns vary in strength, position, and even shape. For example, the May and June precipitation patterns show opposite signs to the July-August or annual mean patterns, whereas the September-December monthly precipitation anomalies show a triple pattern. Monthly precipitation patterns over East China are largely determined by large-scale moisture transport controlled by atmospheric circulation. The PDO affects East China precipitation patterns by modulating the large-scale circulation pattern.
\end{abstract}

\section{Introduction}

The East Asian Summer Monsoon weakened in the late 1970s (Wang 2001; Zhou et al. 2009), which led to significant rainfall changes over East China with more precipitation in the South (south of the Yangtze River Valley) and less in the North. This North-South dipole pattern of precipitation anomalies has often been referred to as "southern flooding and northern drought" ("SF-ND", hereafter) in China (Yatagai and Yasunari 1994; Nitta and Hu 1996; Zhou et al. 2009; Li et al. 2010).

This article is part of a Special Issue on "Mechanism of Decadal-Scale Drought and its Impact on the Ecological Systems and Water Resources over Global Arid and Semi-arid RegionsEndFragment” edited by Zong-Liang Yang and Zhuguo Ma.

Electronic supplementary material The online version of this article (doi:10.1007/s10584-016-1662-9) contains supplementary material, which is available to authorized users.

Zhuguo Ma

mazg@tea.ac.cn

1 Key Laboratory of Regional Climate-Environment for Temperate East Asia, Institute of Atmospheric Physics, Chinese Academy of Sciences, Beijing 100029, China

2 University of Chinese Academy of Sciences, Beijing 100049, China 
Precipitation anomalies over East China and the associated atmospheric circulation are largely influenced by the Sea Surface Temperature (SST; Wang et al. 2000; Yang and Lau 2004; Li et al. 2010; Zhu et al. 2011). In the late 1970s, the Pacific Decadal Oscillation (PDO; Mantua et al. 1997; Mantua and Hare 2002), a leading mode of interdecadal variability in the North Pacific SSTs, experienced a phase change from cold to warm (warm phase corresponds negative SST anomalies in the central North Pacific and positive ones along the west coast of the Americas, and vice versa). Large-scale atmospheric circulations over the Northern Hemisphere and precipitation anomalies over East China also experienced a significant interdecadal shift in the late 1970s (Trenberth and Hurrell 1994; Zhu and Yang 2003). Recently, it was suggested that the PDO has changed from a warm phase to a cold one in the late 1990s and early 2000s (Deser et al. 2004; Zhu et al. 2011; Dai 2012; Qian and Zhou 2014). The recent transition has been found to be the main reason behind the large decreases in precipitation over the Northwest and Southeast US (Dai 2012), and the interdecadal changes in summer precipitation over East China (Zhu et al. 2011). Therefore, the PDO has a strong effect on the interdecadal variations of the East Asian Summer Monsoon and rainfall over East China (Chang et al. 2000; Yang and Lau 2004; Zeng et al. 2007; Li et al. 2010).

On interdecadal time scales, a positive precipitation anomaly over North China coincides with a negative anomaly over South China, and vice versa, which resembles a "seesaw" structure modulated by the PDO. During the warm phase of PDO, the precipitation is below normal with more drought over North China, whereas more rainfall and flooding occur in the middle and lower reaches of the Yangtze River Valley and the southeastern coast of China (Ma and Fu 2006; Ma and Shao 2006; Ma 2007; Zhou et al. 2013; Zhu and Yang 2003). During the cold phase, rainfall concentrates over North China, resulting in above-normal precipitation and more wet conditions over North China but less precipitation and more drought over South China (Zhou and Huang 2003; Gu et al. 2005). Therefore, the PDO is a major contributor to the interdecadal shift of the precipitation pattern over East China, from the "southern drought and northern flooding" ("SD-NF") to the "SF-ND" in the late 1970s (Zhu and Yang 2003; Gu et al. 2005; Ma 2007; Li et al. 2010; Zhou et al. 2013; Qian and Zhou 2014).

The precipitation over East China is largely controlled by the monsoon circulation. Therefore, its interdecadal variability reflects the seasonality (Yang and Lau 2004). The interdecadal variability of summer rainfall shows similar characteristics to the interdecadal shift in annual rainfall (from the "SD-NF" to the "SF-ND") in the late 1970s. During 1951-1998, spring precipitation showed a long-term increasing trend over southeastern China and decreasing trend over central eastern China (Yang and Lau 2004). Moreover, the spring precipitation over South China exhibited an apparent interdecadal shift in the late 1980s: a $30 \%$ reduction over southeastern China and a double increase over southwestern China with respect to prior years (Zuo et al. 2012). Autumn precipitation over East China decreased during 1959-2008 and the rate has accelerated since the 1980s (Chen et al. 2012). Winter precipitation over most of East China increased during 1960-2008 and showed a decadal variation around mid-1980s, following the weakening of the East Asian Winter Monsoon (Sun and Ao 2013).

Clearly, the interdecadal variability of precipitation over East China presents distinct seasonality, which is attributed to several external factors, like the seasonal-dependent upper tropospheric cooling (Yu and Zhou 2007), the zonal climatic teleconnection pattern and anomalous Indian summer monsoon precipitation (Huang et al. 2015). On the other hand, modulation of the PDO on the local precipitation has also been studied. The summer precipitation over South China is modulated by the PDO through ENSO-related SST anomaly (Mao et al. 2011; Duan et al. 2013). Ma and Shao (2006) found that the PDO is closely related to the dry/wet variation of northern China. 
However, it remains unclear whether the PDO has affected the seasonal precipitation over the whole East China. In this study two questions will be addressed in this study: 1) whether the North-South dipole pattern only exists in the summer and 2) what dominates the pattern shift of monthly precipitation over East China (if it exists) during the different phases of PDO.

This paper is organized as follows: Section 2 introduces the data and method; Section 3 presents the results; a preliminary quantitative discussion about the PDO's impact on precipitation is provided in Section 4; and a summary is given in Section 5.

\section{Data and method}

Several datasets are used in this study. (1) The 160-station monthly precipitation dataset from 1951 to 2013 and the 60-station long-term precipitation dataset from 1908 to 2013, both of which are obtained from the China Meteorological Administration. (2) Global land monthly precipitation from 1901 to 2012 with high resolution of $0.5^{\circ} \times 0.5^{\circ}$ from the Climate Research Unit (CRU TS3.21, refer to Harris et al. 2014). (3) Global land monthly precipitation from 1901 to 2010 with resolution of $0.5^{\circ} \times 0.5^{\circ}$ from the Global Precipitation Climatology Centre (GPCC, refer to Schneider et al. 2011). (4) The monthly PDO index from 1900 to 2013 (Mantua et al. 1997; Zhang et al. 1997), defined as the leading standardized principal component of monthly SST anomalies in the North Pacific Ocean (http://jisao.washington.edu/pdo/ PDO.latest). Finally, (5) the US National Centers for Environmental Prediction/National Center for Atmospheric Research (NCEP/NCAR) (1948-2013; Kalnay et al. 1996), the European Centre for Medium-Range Weather Forecasts (ERA40) (1958-2002; Uppala et al. 2005), and the Japanese 55-year (JRA-55) (1958-2013; Ebita et al. 2011) reanalysis datasets of atmospheric geopotential height, winds, surface pressure and specific humidity.

Composite analysis of the PDO different phases was performed to obtain the spatial anomaly patterns of precipitation and atmospheric circulation. $t$-test (Wilks 2005) was used to give the significance of difference between two time series (refer to the Supplement A1). To detect the relation between precipitation and the PDO on interdecadal time scales, the Ensemble Empirical Mode Decomposition method (EEMD, Huang and Wu 2008; Wu and Huang 2009) was used (refer to the Supplement A2), which is a recently developed data-adaptive filter for nonlinear and nonstationary time series analysis. It has been used to distinguish the decadal/interdecadal variations of global temperature, precipitation, aridity index, etc., from the observations dataset, and the results show clear physical significance (Wu et al. 2011; Xia et al. 2013; Qian and Zhou 2014). In this study, the EEMD method was used to extract the components of the interdecadal variability of regional mean precipitation and the PDO series.

The contribution of the PDO on the precipitation over East China is quantified by:

$$
q=\left|\frac{P_{w}-P_{c}}{P}\right| \times 100 \%
$$

where $P_{w}$ and $P_{c}$ are the averages of interdecadal precipitation (extracted by the EEMD method) during the warm (1977-2002) and cold (1945-1976) phases of PDO, respectively, $P$ the average (1945-2002) of raw precipitation, | | the absolute, and $q$ the contribution rate of the PDO on precipitation. The interdecadal precipitation extracted by the EEMD method represents the component modulated by the PDO, therefore, the difference between the averages during different phases of PDO is resulted from the PDO. 
Finally, because the names of the regions are often confused, it is necessary to define them. In this study, South China denotes the region of the middle and lower reaches of the Yangtze River Valley and south of it $\left(110-122^{\circ} \mathrm{E}, 22-30^{\circ} \mathrm{N}\right)$, North China denotes the region north of the lower reaches of the Yellow River Valley $\left(110-117.5^{\circ} \mathrm{E}, 35-42.5^{\circ} \mathrm{N}\right)$. Both are included in East China, which is the region east of $100^{\circ} \mathrm{E}$ and south of $42^{\circ} \mathrm{N}$.

\section{Results}

\subsection{Precipitation variability over East China and its links to the PDO}

\subsubsection{Annual precipitation}

On interdecadal time scales, annual precipitation over East China shows alternating "SD-NF" or "SF-ND" anomalies, resembling a "seesaw" structure. These patterns of precipitation anomalies are modulated by the PDO, as shown in Fig. 1. According to previous studies, the recent two phases transitions of the PDO occurred in the late 1970s and around 2000 (Qian and Zhou 2014). Therefore, composite analysis is performed for 1951-1976, 1977-2002, and 2003-2013. During the PDO cold phase (1951-1976), the "SD-NF" pattern is seen (Fig. 1a). In this period, there was more precipitation over North China and less over South China. During the PDO warm phase (1977-2002), the precipitation anomaly pattern reversed: negative anomalies over North China and positive anomalies over South China, corresponding to the "SF-ND" structure (Fig. 1b). The composite average during the recent cold phase (2002-2013) clearly shows the "SD-NF" structure of the precipitation anomalies (Fig. 1c), although this phase is not complete.

To show the interdecadal correlation between annual precipitation and the PDO, interdecadal components of the PDO index and area mean precipitation over North and South China are extracted using the EEMD method, respectively. Observations, CRU and GPCC datasets all show clearly that annual precipitation and the PDO are out of phase over North China (Fig. 2a) and nearly in phase over South China, but lagging by 5-12 years, despite the differences among the three datasets (Fig. 2b). For example, precipitation shows positive anomalies over North China and negative anomalies over South China during the cold phase. These results are consistent with the spatial characteristics of the precipitation anomalies in Fig. 1.

\subsubsection{Monthly precipitation}

The meridional structures of the zonal-mean precipitation anomalies over East China during three phases of the PDO are shown in Fig. 1d-f. Similar to annual precipitation, the July and August precipitation shows similar interdecadal variability (Fig. 1d and e): there are positive and negative anomalies over North and South China, respectively, during the cold phase and opposite anomalies during the warm phase. These anomalies correspond to the North-South dipole pattern of annual precipitation (Fig. 1a and b).

However, there are some differences in the May and June precipitation. During the cold phase of PDO, there is a strong positive precipitation anomaly over South China and a negative precipitation anomaly north of it, corresponding to the "SF-ND" pattern. During the warm phase, the pattern changes into "SD-NF." Apparently, the patterns in May and June 
(a) $\mathrm{PDO}(-) \quad 1951-1976$

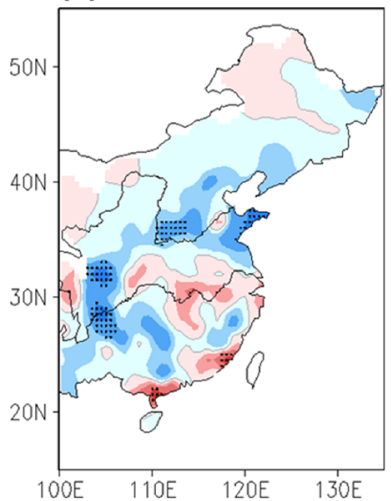

(b) $\mathrm{PDO}(+)$ 1977-2002

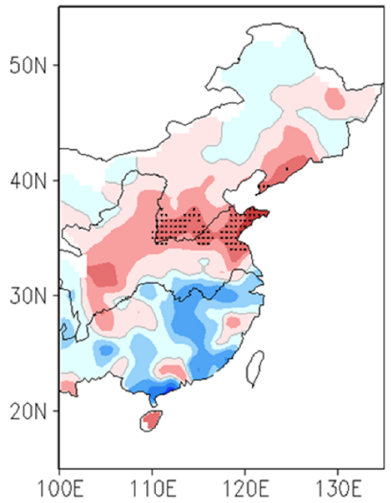

(c) $\mathrm{PDO}(-) 2003-2013$

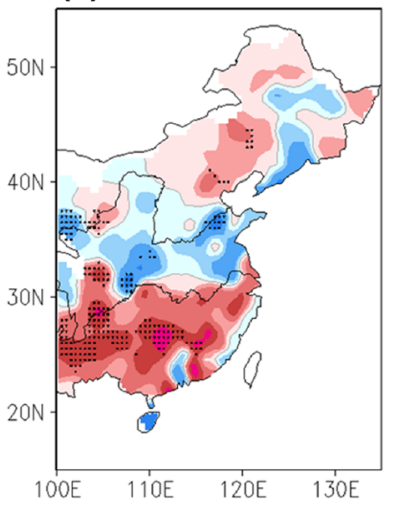

(d) $\mathrm{PDO}(-) 1951-1976$

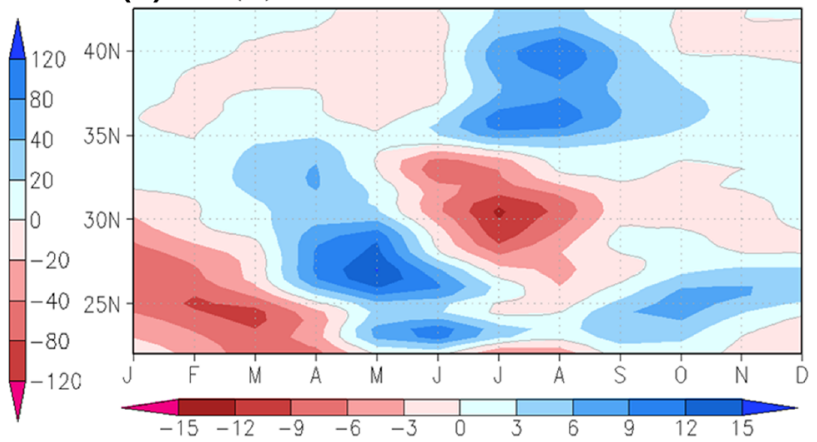

(e) $\mathrm{PDO}(+)$ 1977-2002

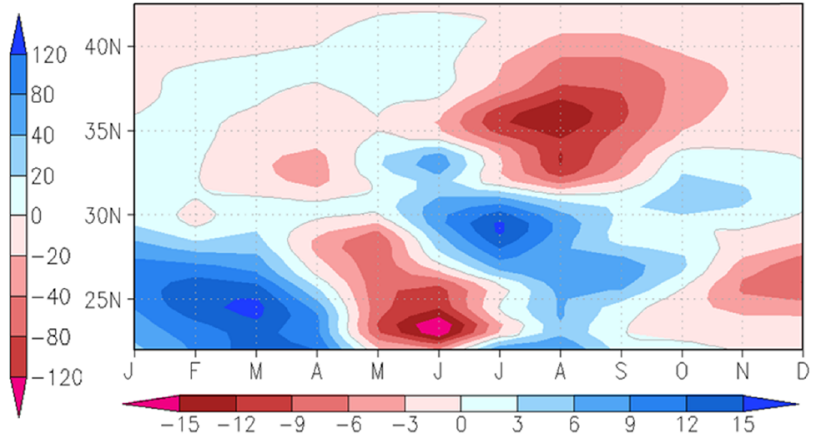

(f) $\mathrm{PDO}(-) 2003-2013$

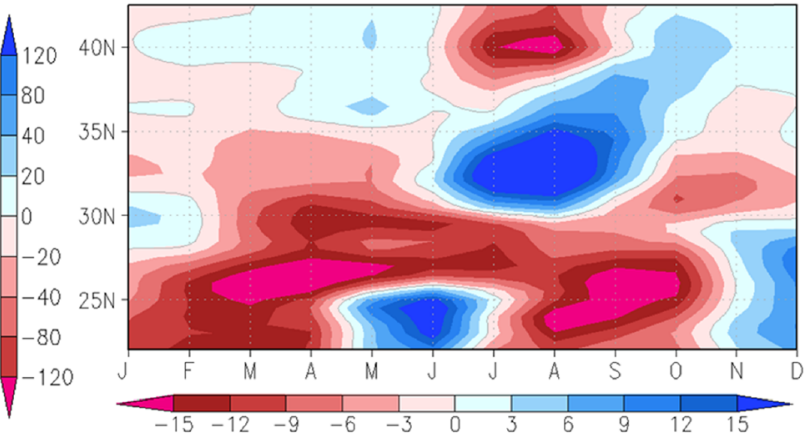

Fig. 1 Annual precipitation anomalies (left, in $\mathrm{mm}$ ) and the meridional structure of monthly precipitation anomalies (right, in $\mathrm{mm}$ ) with respect to the climatology from 1951 to 2013 during three PDO phases: a, d 1951-1976, b, e 1977-2002, and c, f 2003-2013, using the observation dataset. Stippled areas in (a-c) denote anomalies that are statistically significant at the $90 \%$ level. Precipitation in $(\mathbf{d}-\mathbf{f})$ is averaged from $110^{\circ} \mathrm{E}$ to $117^{\circ} \mathrm{E}$

are opposite to the annual precipitation pattern. Besides, the position of precipitation anomalies is different. The division between the positive and negative anomalies is around $30^{\circ} \mathrm{N}$ in May and moves southward to about $27^{\circ} \mathrm{N}$ in June. 
Fig. 2 The interdecadal variabilities of the PDO index and annual precipitation, both of which are extracted using the EEMD method over a North China (110$\left.117.5^{\circ} \mathrm{E}, 35-42.5^{\circ} \mathrm{N}\right)$ and $\mathbf{b}$ South China $\left(110-122^{\circ} \mathrm{E}, 22-30^{\circ} \mathrm{N}\right)$ from observation, CRU and GPCC datasets, respectively (a) North China

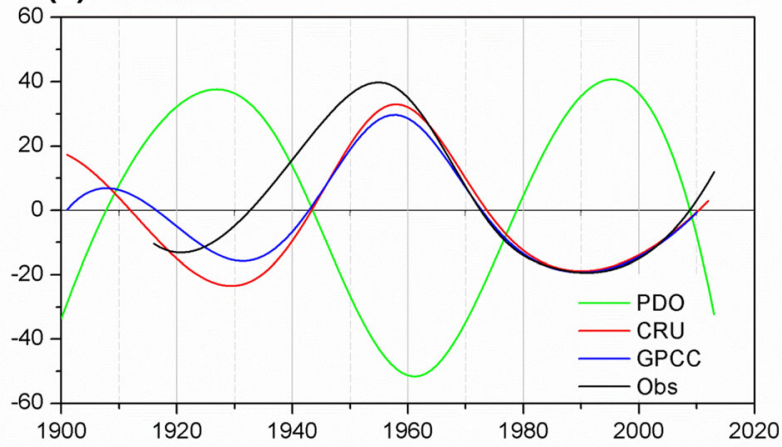

(b) South China

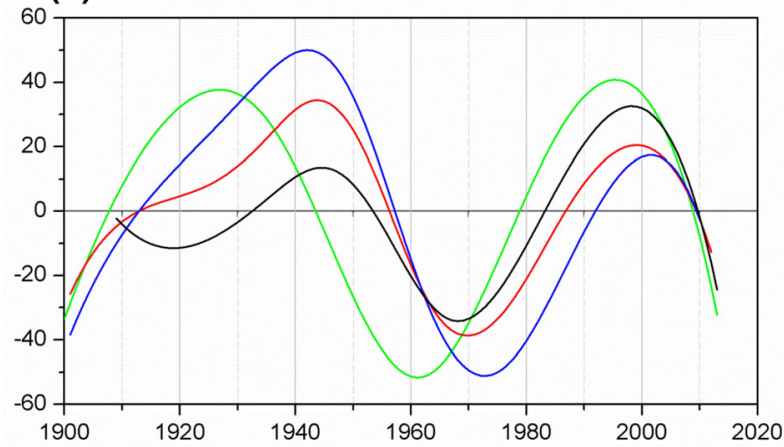

For the January to April precipitation, there are negative anomalies over south of $32^{\circ} \mathrm{N}$, which move gradually from the middle and lower reaches of the Yangtze River Valley in January to the southeastern coast in April during the cold phase of PDO. Moreover, there are positive anomalies over north of $32^{\circ} \mathrm{N}$ although relatively weak. An opposite pattern of precipitation anomalies is found during the warm phase of PDO. This means that the pattern of "SD-NF" and "SF-ND" is presented in the January-April precipitation during the cold and warm phase of PDO, respectively. However, the anomalous precipitation centers move southward with respect to the annual precipitation anomalies pattern. For instance, the positive anomalies in April occur only around south of $25^{\circ} \mathrm{N}$ during the cold phase of PDO, whereas the corresponding anomalies are around $34^{\circ} \mathrm{N}$ in the annual precipitation.

For September to December precipitation, there is more precipitation over most of East China except the negative precipitation anomalies in central eastern China, corresponding to a triple structure of " +-+ " during the cold phase of PDO. Besides more precipitation in central eastern China, negative precipitation anomalies are seen over most of East China with a triple structure of "- + -" that corresponds to the warm phase of PDO.

It should be noted that there are some differences between the precipitation anomalies during the two cold phases (Fig. 1a, c, d and f). In fact, compared with the entire cold phase of 1945-1976, SST in the central North Pacific is colder by about $0.1{ }^{\circ} \mathrm{C} \sim 0.3{ }^{\circ} \mathrm{C}$ during the first decade of the present cold phase. Therefore, the modulation of PDO on precipitation is likely different. However, the main characteristics are still recognizable in this incomplete phase, such as the "SD-NF" in July and August and the "SF-ND" in May and June. 
Additionally, the precipitation in East China is influenced by several external factors that possess various time-scales. In this study, the composite analysis is used to extract the contribution of the PDO on the precipitation. The periods used in the composite analysis of precipitation are strictly taken from those of cold and warm phases of PDO. For the external factor with the period shorter than the PDO (like ENSO), its contribution on the precipitation will be counteracted each other in a single phase of PDO. For the external factor with the period longer than the PDO (like AMO), its contribution will sustain for more than a phase of PDO, such that the results of composite analysis will not be reversed during different phases of PDO. However, from the results of composite analysis (Fig. 1), the patterns of precipitation anomalies present almost reversed characteristics, suggesting that the contributions of external factors with longer periods are neglectable. Therefore, the results of composite analysis (Fig. 1) can be attributed to the PDO.

Figure 3 shows the correlation coefficients for the interdecadal components of the PDO index and monthly precipitation over North China and South China, respectively. Besides May, monthly precipitation over North China exhibits significant negative correlation with the PDO on interdecadal time scales (Fig. 3a). However, interdecadal correlations between precipitation over South China and the PDO display clear seasonal characteristics (Fig. 3b), although there are some differences among the three datasets. As shown in Fig. 3, correlation coefficients are negative over North China and positive over South China from January to April, and July and August. This corresponds to the "SF-ND" ("SD-NF") pattern during the
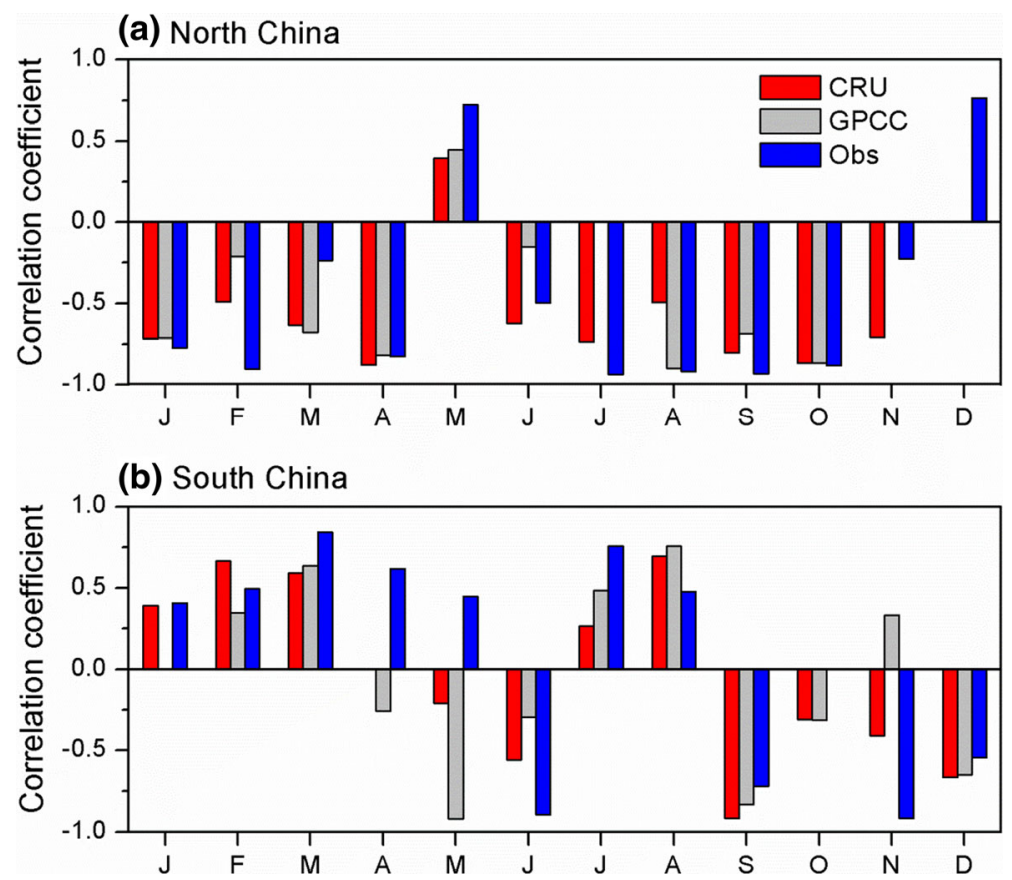

Fig. 3 Correlation coefficients between the interdecadal variabilities of the PDO index and monthly precipitation, both of which are extracted using the EEMD method, over a North China and b South China from observations, CRU and GPCC datasets, respectively. Correlation coefficients that are not statistically significant at the $95 \%$ level have been removed 
warm (cold) phase of PDO. In May, there are positive and negative correlation coefficients over North China and South China, respectively, corresponding to the "SD-NF"("SF-ND") pattern during the warm (cold) phase of PDO. However, negative correlation coefficients are both found over North and South China in June. This is because the NorthSouth dipole pattern in June shifted southward and is limited in the south of $35^{\circ} \mathrm{N}$ (Fig. 1d and e). Clearly, the anomalous precipitation center in the north is not located at North China but at the middle and lower reaches of the Yangtze River Valley. During September to December, there are negative correlation coefficients over North and South China, corresponding to less (more) rainfall over most of East China during the warm (cold) phase of PDO.

In general, the modulation by the PDO of monthly precipitation over East China is monthdependent. The North-South dipole pattern does not occur exclusively in July and August. There are also similar (during January-April) or opposite (in May and June) structures in other months.

\subsection{Mechanisms for the PDO's effect on precipitation variability}

How do SST anomalies (the PDO) affect monthly precipitation of East China? What dominates the differences of monthly precipitation during the cold and warm phases of PDO? East China locates in the East Asia monsoon region, with abundant moisture from the Indian Ocean, the Bay of Bengal, South China Sea and the West Pacific (refer to Supplement A4 for climatology). As first step, the differences of atmospheric circulations and moisture transportation between the cold (1958-1976) and warm (1977-2001) phases of PDO are investigated using the EAR40 reanalysis (Fig. 4). To simplify the discussion, only April, June, and August are presented as typical cases of the January-April, May-June, and July-August periods, respectively.

With respect to the climatology, there are high (low) pressure anomalies over North Pacific at $500 \mathrm{hPa}$ in April during the cold (warm) phase of PDO. The wind difference (Fig. 4a, arrows) presents anomalous easterly winds over South China and southeasterly winds over North China that promotes the northward transport of moisture. Consequently, there are anomalous moisture convergence (divergence) over the middle and lower reaches of the Yangtze River Valley and North China, anomalous moisture divergence (convergence) over the most area of South China during the cold (warm) phase (Fig. 4b). The pattern of moisture divergence corresponds to the precipitation structure of "SD-NF" and "SF-ND" in April during the cold and warm phases, respectively (Fig. 1d-e).

With respect to the climatology, the West Pacific Subtropical High is weaker (stronger) at $500 \mathrm{hPa}$ in June during the cold (warm) phase (Fig. 4c). Correspondingly, the southwesterly winds are weakened (strengthened) along the northwestern flank of the West Pacific Subtropical High, the region of the middle and lower reaches of the Yangtze River Valley. Therefore, the northward transport of moisture from the Bay of Bengal and South China Sea is inhibited (promoted) to the middle and lower reaches of the Yangtze River Valley during the cold (warm) phase, leading to anomalous divergence (convergence) there and convergence (divergence) south of it (Fig. 4d). This results in less (more) precipitation over the middle and lower reaches of the Yangtze River Valley and more (less) over its south during the cold (warm) phase. This corresponds to the precipitation pattern in June as shown in Fig. 1d-f. 
(a) Apr 500hpa $z_{\text {; UV }}$

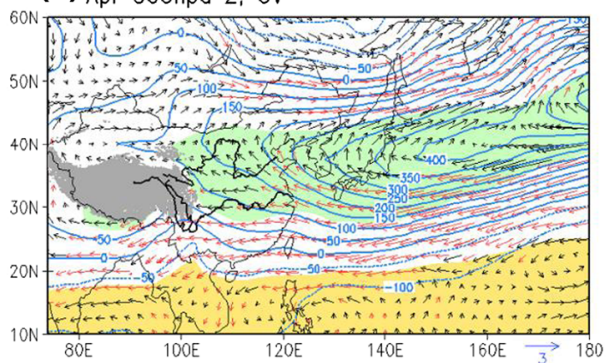

(c) Jun 500hpa Z; UV

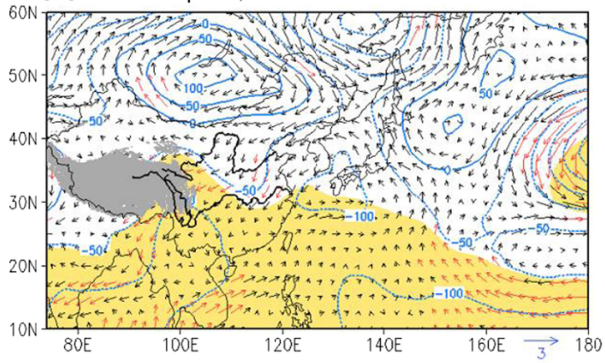

(e) Aug 500hpo $z_{i}$ uV

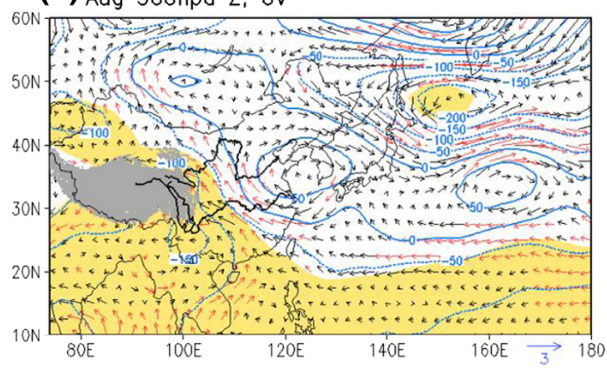

(b) Apr surface-700hpa moisture

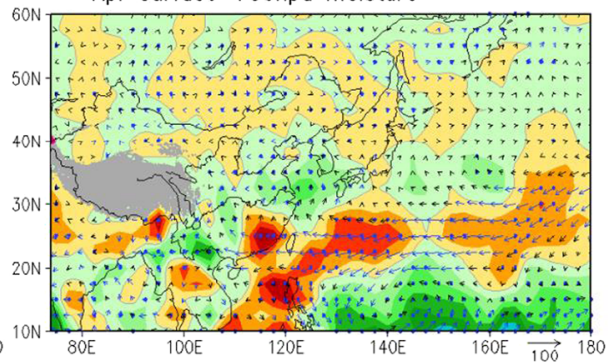

(d) Jun surface-700hpa moisture

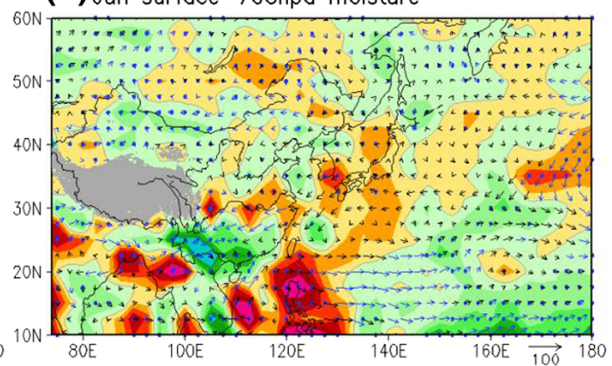

(f) Aug surface-700hpa moisture

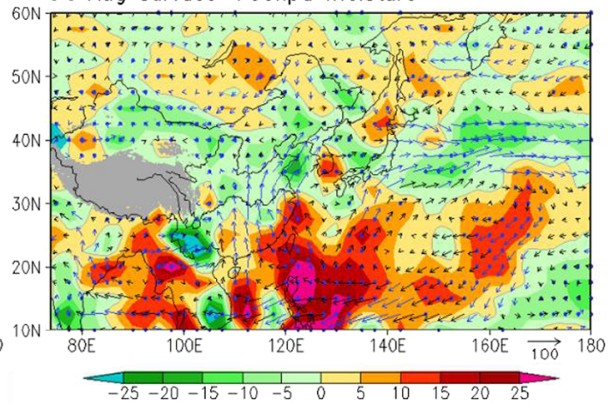

Fig. 4 The differences of (left) $500 \mathrm{hPa}$ geopotential height $\left(0.1 \mathrm{~m}\right.$ contour), winds ( $\mathrm{m} \mathrm{s}^{-1}$, vector), (right) moisture flux $\left(10^{2} \mathrm{~kg} \mathrm{~m}^{-1} \mathrm{~s}^{-1}\right.$, vectors $)$ and moisture divergence $\left(2 \times 10^{-2} \mathrm{~kg} \mathrm{~m}^{-2} \mathrm{~s}^{-1}\right.$, shaded) integrated from the surface to $700 \mathrm{hPa}$ in a, b April, c, d June and e, f August between the periods 1958-1976 and 1977-2001, from the ERA40 Reanalysis. The shaded areas and red arrows denote the differences that are statistically significant at the $90 \%$ level in the left column. Blue points and arrows indicate the differences that are statistically significant at the $90 \%$ level in the right column. Gray areas are the Tibetan Plateau

With respect to the climatology, the southerly winds over East China in August is strengthened (weakened), caused by an anomalous anticyclone (cyclonic) over East Asia, during the cold (warm) phase (Fig. 4e), which promotes (inhibits) the northward transport of the moisture. Therefore, there are anomalous moisture convergence (divergence) over North China and divergence (convergence) over the middle and lower reaches of the Yangtze River Valley during the cold (warm) phase. This leads to more (less) precipitation over North China and less (more) over South China during the cold (warm) phase of PDO, corresponding to the "SD-NF" (“SF-ND”) pattern (Fig.1d-e).

The atmospheric conditions in April, June, and August from the JRA-55 Reanalysis are comparable to the above results from the ERA40 Reanalysis. This suggests that the patterns of atmospheric circulation anomalies modulated by the PDO are robust in the different datasets. 


\section{Discussion}

It is interesting to quantify the contribution of the PDO on the annual and monthly precipitation using Eq. (1). For annual precipitation over North China, anomalies of $24.0 \mathrm{~mm}$ and $-16.5 \mathrm{~mm}$ (observation) occur during the cold (1945-1976) and warm (1977-2002) phases of PDO, respectively; while For South China, anomalies of $-14.8 \mathrm{~mm}$ and $14.2 \mathrm{~mm}$ occur. Therefore, annual precipitation variations induced by the PDO are $-40.5 \mathrm{~mm}$ and $29.0 \mathrm{~mm}$ over North and South China. It suggests that the modulation of PDO on the precipitation over South China is less significant than that over North China, which can be explained by the fact that the precipitation over South China is influenced by several other factors except the PDO. According to Eq. (1), the contribution rates are $7.6 \%$ and $1.9 \%$ over North and South China, respectively. Why is the contribution rate over North China much larger than that over South China? In fact, the mean annual precipitation (1945-2002) are $537.5 \mathrm{~mm}$ and $1500.0 \mathrm{~mm}$ over the North and South China, respectively. As the annual precipitation i.e., $P$ in Eq. (1), is relatively large for the South China, with respect to the North China, the contribution rate over South China is relatively small.

For the monthly precipitation, the contribution rates from observation, CRU and GPCC dataset are shown in Fig. 5. In general, the contribution rate (averaged over observation, CRU and GPCC dataset) over North China varies from $3.1 \%$ (July) to $18.6 \%$ (April). For the South China, it varies from $2.3 \%$ (May) to $11.2 \%$ (December). Moreover, for both North and South China, contribution rates of the PDO on summer precipitation (June, July and August) are weaker than other months. For instance, the mean contribution rates are only $4.5 \%$ and $4.6 \%$ over North and South China, respectively. In other words, the PDO's impact on summer may be relatively weak over East China, with respect to other seasons.

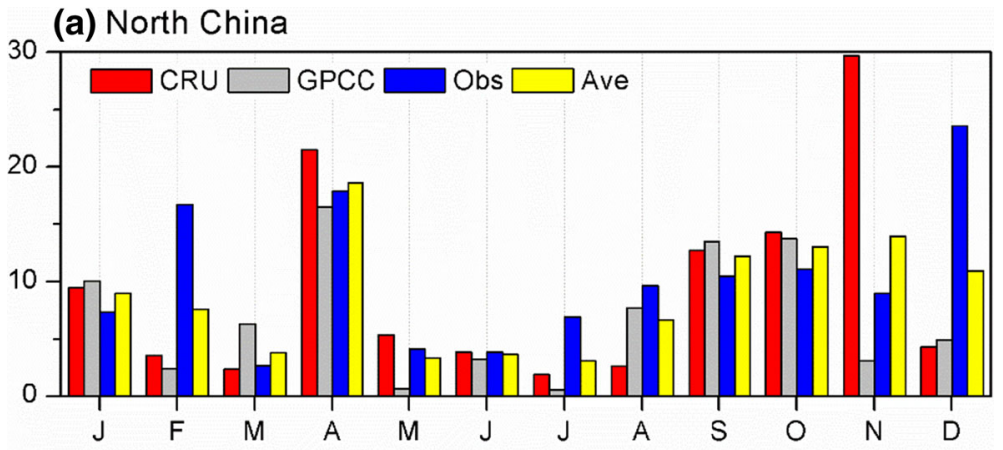

(b) South China

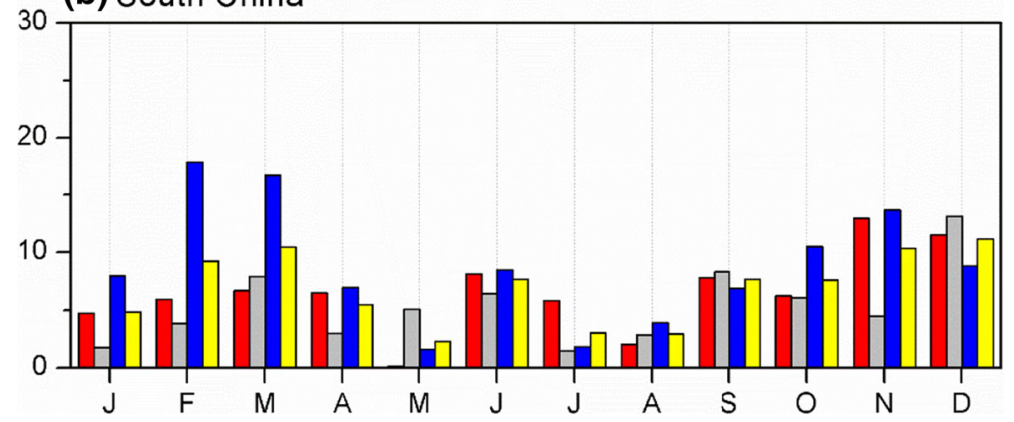

Fig. 5 Contribution rates (\%) of the PDO on monthly precipitation over a North China and b South China from observations, CRU, GPCC datasets and the average of these three dataset, respectively 


\section{Summary}

According to previous studies, annual precipitation anomalies over East China are modulated by the PDO; negative (positive) anomalies over South China and positive (negative) anomalies over North China, i.e., "southern drought and northern flooding" ("southern flooding and northern drought") patterns during the cold (warm) phases of PDO. This study has primarily focused on the modulation of PDO on monthly precipitation. Using observations, CRU and GPCC precipitation datasets, temporal-spatial features of the PDO-induced monthly precipitation anomalies and atmospheric circulation over East China were investigated. The main conclusions are the following.

1) On interdecadal time scales, annual precipitation anomalies are out of phase with the PDO over North China and in phase over South China but lagging by 5-12 years. This suggests that the North-South dipole pattern of annual precipitation over East China is nonsynchronous.

2) The modulation by the PDO on monthly precipitation anomalies is month-dependent. During the warm phase of the PDO, the "SF-ND" pattern of precipitation anomalies during January to April is similar to that of annual precipitation, except for the division of positive and negative anomalies that moves southward and the anomalies over North China that are relatively weak. For May and June precipitation, there are "SD-NF" patterns, which are opposite to annual precipitation anomalies, and the division between positive and negative anomalies moves southward gradually from around $30^{\circ} \mathrm{N}$ in May to about $27^{\circ} \mathrm{N}$ in June. For July and August precipitation, the anomalies follow the "SF-ND" pattern, essentially the same with the annual precipitation anomalies. For September-December precipitation, there is less precipitation over most of East China except the positive precipitation anomalies in central East China, corresponding to a weak triple structure of "- +-". Opposite patterns of monthly precipitation anomalies correspond to the cold phase of the PDO.

3) The North-South dipole pattern of annual precipitation does not occur exclusively in the summer. There are similar or opposite structures in other months. Even in the summer, the pattern of precipitation anomalies in June is largely different from that in July and August. This answers the first question in the introduction: the PDO modulates monthly precipitation anomalies over East China and its effect is month-dependent.

4) The modulation of PDO on the precipitation is quantified using the contribution rate. For the annual precipitation, the contribution rates are $7.6 \%$ and $1.9 \%$ over North and South China, respectively. For the monthly precipitation, the contribution rate over North China varies from $3.1 \%$ (July) to $18.6 \%$ (April), while for South China, it varies from $2.3 \%$ (May) to $11.2 \%$ (December).

5) Anomalous moisture flux and divergence presumably explain the monthly precipitation anomalies modulated by the PDO, which partially answers the second question in the introduction.

These preliminary results suggest that the PDO modulates precipitation anomalies over East China by adjusting moisture transportation. However, the detailed dynamic processes remain unclear and require further investigation in the future.

Acknowledgments This research was supported by the National Basic Research Program of China (2012CB956201), the National Key Technology R \& D Program of China (2013BAC10B02), China Special Fund for Meteorological Research in the Public Interest (GYHY201506001-1), and the National Natural Science Foundation of China (41275085; 41530532). 
Open Access This article is distributed under the terms of the Creative Commons Attribution 4.0 International License (http://creativecommons.org/licenses/by/4.0/), which permits unrestricted use, distribution, and reproduction in any medium, provided you give appropriate credit to the original author(s) and the source, provide a link to the Creative Commons license, and indicate if changes were made.

\section{References}

Chang CP, Zhang YS, Li T (2000) Interannual and interdecadal variations of the East Asian summer monsoon and tropical Pacific SSTs. Part I: Roles of the subtropical ridge. J Clim 13:4310-4325

Chen S, Huang J, Fu Q, Ge J, Su J (2012) Effects of aerosols on autumn precipitation over mid-Eastern China. J Trop Meteorol 27:339-347

Dai A (2012) The influence of the inter-decadal Pacific oscillation on US precipitation during 1923-2010. Clim Dyn 41:633-646

Deser C, Phillips AS, Hurrell JW (2004) Pacific interdecadal climate variability: Linkages between the tropics and the North Pacific during boreal winter since 1900. J Clim 17:3109-3124

Duan W, Song L, Li Y, Mao J (2013) Modulation of PDO on the predictability of the interannual variability of early summer rainfall over South China. J Geophys Res Atmos 118:1-14

Ebita A, Kobayashi S, Ota Y, Moriya M, Kumabe R, Onogi K, Harada Y, Yasui S, Miyaoka K, Takahashi K, Kamahori H, Kobayashi C, Endo H, Soma M, Oikawa Y, Ishimizu T (2011) The Japanese 55-year reanalysis "JRA-55": an Interim Report. Sola 7:149-152

$\mathrm{Gu}$ W, Li C, Yang H (2005) Analysis on interdecadal variations of summer rainfall and its trend in East China. Acta Meteorol Sin 63:728-739

Harris I, Jones PD, Osborn TJ, Lister DH (2014) Updated high-resolution grids of monthly climatic observations - the CRU TS3.10 dataset. Int J Climatol 34:623-642

Huang NE, Wu Z (2008) A review on Hilbert-Huang transform: method and its applications to geophysical studies. Rev Geophys 46

Huang W, Chen J, Zhang X, Feng S, Chen F (2015) Definition of the core zone of the "westerlies-dominated climatic regime", and its controlling factors during the instrumental period. Sci China Earth Sci 58:676-684

Kalnay E et al. (1996) The NCEP/NCAR 40-year reanalysis project. Bull Am Meteorol Soc 77:437-471

Li H, Dai A, Zhou T, Lu J (2010) Responses of East Asian summer monsoon to historical SST and atmospheric forcing during 1950-2000. Clim Dyn 34:501-514

Ma Z (2007) The interdecadal trend and shift of dry/wet over the central part of North China and their relationship to the Pacific Decadal Oscillation (PDO). Chin Sci Bull 52:2130-2139

Ma Z, Fu C (2006) Some evidence of drying trend over Northern China from 1951 to 2004. Chin Sci Bull 51: 2913-2925

Ma Z, Shao L (2006) Relationship between dry/wet variation and the Pacific Decade Oscillation (PDO) in Northern China during the Last 100 years. China J Atmos Sci 30:464-474

Mantua NJ, Hare SR (2002) The Pacific decadal oscillation. J Oceanogr 58:35-44

Mantua NJ, Hare SR, Zhang Y, Wallace JM, Francis RC (1997) A Pacific interdecadal climate oscillation with impacts on salmon production. Bull Am Meteorol Soc 78:1069-1079

Mao J, Chan J, Wu G (2011) Inter-annual variations of early summer monsoon rainfall over South China under different PDO backgrounds. Int J Climatol 31:847-862

Nitta T, Hu ZZ (1996) Summer climate variability in China and its association with $500 \mathrm{hPa}$ height and tropical convection. J Meteorol Soc Jpn 74:425-445

Qian C, Zhou T (2014) Multidecadal variability of North China aridity and its relationship to PDO during 19002010. J Clim 27:1210-1222

Schneider U, Becker A, Finger P, Meyer-Christoffer A, Rudolf B, Ziese M (2011) GPCC full data reanalysis version 6.0 at $0.5^{\circ}$ : monthly land-surface precipitation from rain-gauges built on gts-based and historic data. doi:10.5676/DWD GPCC/FD M V7 050

Sun J, Ao J (2013) Changes in precipitation and extreme precipitation in a warming environment in China. Chin Sci Bull 58:1395-1401

Trenberth KE, Hurrell JW (1994) Decadal Atmosphere-Ocean variations in the Pacific. Clim Dyn 9:303-319

Uppala SM et al. (2005) The ERA-40 re-analysis. Q J R Meteorol Soc 131:2961-3012

Wang HJ (2001) The weakening of the Asian monsoon circulation after the end of 1970's. Adv Atmos Sci 18:376-386

Wang B, Wu RG, Fu XH (2000) Pacific-East Asian teleconnection: how does ENSO affect east Asian climate? J Clim 13:1517-1536

Wilks, D.S., 2005: Statistical methods in the atmospheric sciences: second editon. International Geophysics Series, 91:141 
Wu Z, Huang NE (2009) Ensemble Empirical mode Decomposition: A noise-assisted data analysis method. Adv Adapt Data Anal 1:1-41

Wu Z, Huang NE, Wallace JM, Smoliak BV, Chen X (2011) On the time-varying trend in global-mean surface temperature. Clim Dyn 37:759-773

Xia J, Yan Z, Wu P (2013) Multidecadal variability in local growing season during 1901-2009. Clim Dyn 41: 295-305

Yang F, Lau KM (2004) Trend and variability of China precipitation in spring and summer: Linkage to seasurface temperatures. Int J Climatol 24:1625-1644

Yatagai A, Yasunari T (1994) Trends and Decadal-Scale Fluctuations of surface Air temperature and precipitation over China and Mongolia during the recent 40 year period (1951-1990). J Meteorol Soc Jpn 72:937-957

Yu R, Zhou T (2007) Seasonality and three-dimensional structure of interdecadal change in the east Asian monsoon. J Clim 20:5344-5355

Zeng G, Sun Z, Wang W, LIN Z, Ni D (2007) Interdecadal variation of east Asian SummerMonsoon Simulated by NCAR Cam3 Driven by global SSTs. Clim Environ Res 12:211-224

Zhang Y, Wallace JM, Battisti DS (1997) ENSO-like interdecadal variability: 1900-93. J Clim 10:1004-1020

Zhou L, Huang R (2003) Research on the characteristics of interdecadal variability of summer climate in China and its Possible Cause. Clim Environ Res 8:274-290

Zhou T, Gong D, Li J, Li B (2009) Detecting and understanding the multi-decadal variability of the east Asian summer monsoon - recent progress and state of affairs. Meteorol Z 18:455-467

Zhou T, Song F, Lin R, Chen X, Chen X (2013) The 2012 North China floods: explaining an extreme rainfall event in the context of a longer-term drying tendency [in "explaining extreme Events of 2012 from a climate Perspective"]. Bull Am Meteorol Soc 94:S49-S51

Zhu Y, Yang X (2003) Relationships between Pacific decadal oscillation (PDO) and climate variabilities in China. Acta Meteorol Sin 61:641-654

Zhu Y, Wang H, Zhou W, Ma J (2011) Recent changes in the summer precipitation pattern in East China and the background circulation. Clim Dyn 36:1463-1473

Zuo Z, Zhang R, Wu B (2012) Inter-decadal variations of springtime rainfall over Southern China mainland for 1979-2004 and its relationship with Eurasian snow. Sci China Earth Sc 55:271-278 